Please send trade news information and illustrations to Arveen Bajaj at the $B D J$, Nature Publishing Group, The Macmillan Building, 4-6 Crinan Street, London N1 9XW.

Trade news is provided as a service to readers using text and images from the manufacturer, supplier or distributor and does not imply endorsement by the BDJ. Normal and prudent research should be exercised before purchase or use of any product mentioned.

\section{Easy crown removal}

The WAMkey and WAM'X, are solutions to simple crown and post removal.

WAMkey is a set of three instruments designed to remove crowns quickly, easily and without damaging the margins or the bulk of the crown. The clinician drills a small horizontal hole through the crown at the level of the cement layer until reaching the centre of the preparation.

Then the WAMkey, which has an oval profile, is inserted into the hole and rotated to raise the crown along its vertical axis which means otherwise successful crowns can be reused after any underlying treatment has been completed. When replaced, the access hole is simply sealed with an appropriate shade of composite.

WAM'X is used to remove posts and cores quickly, easily and with reduced risk of fracturing the root. The clinician prepares a narrow slot between the prosthesis and root, into which the prongs of the WAM'X are placed. Simply compressing the grip raises the post and core. The products are available from Quality Endodontic Distributors Ltd.

Reader response number $\mathbf{5 1}$

\section{TRADE NEWS WHAT'S NEW}

\section{New ultrasonic cleaning tablets}

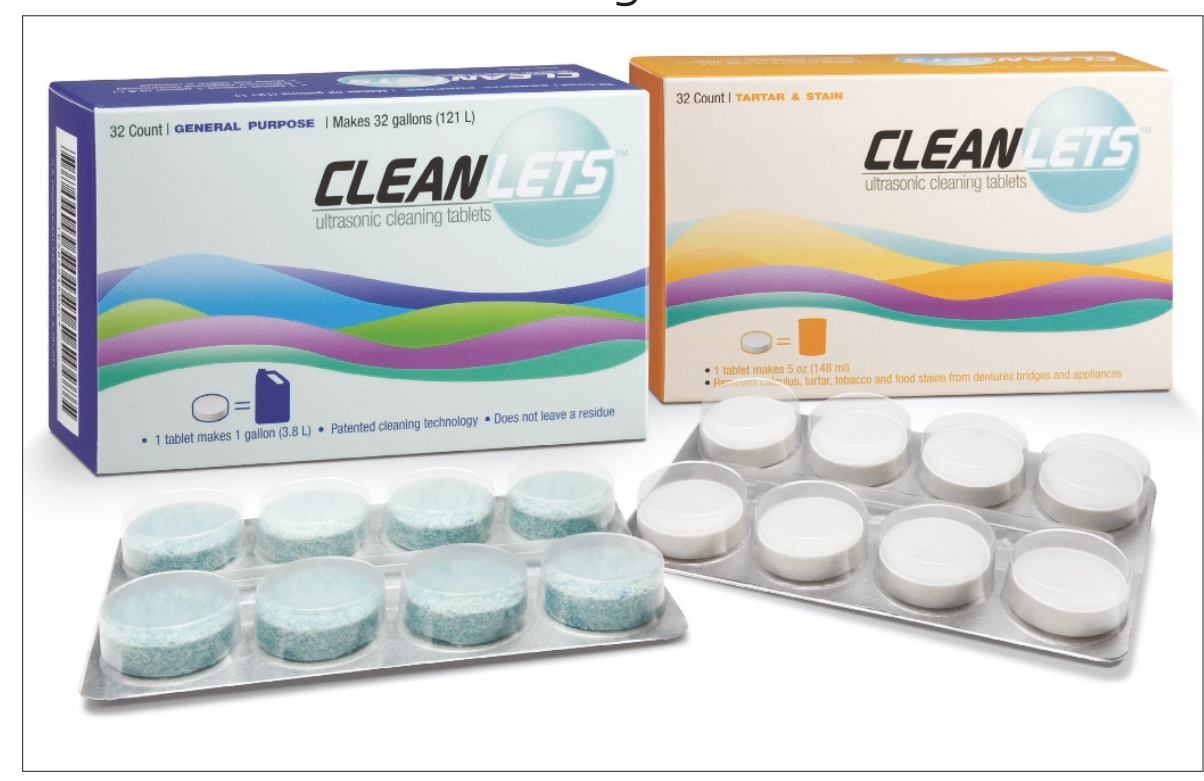

Sultan Healthcare Inc has announced the launch of Cleanlets Ultrasonic Cleaning Tablets. The tablets come in two formulations, general purpose and tartar and stain, offering convenience and excellent value for the user.

They are a lightweight alternative to handling and shipping heavy, liquid containers and their effervescent action makes mixing quick and easy with no residue left in the tank or on instruments.

The product requires only one tablet per gallon compared to the two required by leading competitive tablets, creating a better value on a cost per use basis according to the manufacturers. Its small compact packaging allows the user to gain back valuable office storage space while its blister pack design makes it easy for the customer to dispense and store.

Reader response number 50

\section{Mouthwash with triple defences}

Dentyl pH have recently launched Exhilaration mouthwash, which has a new triple defence capability. It inhibits VSCs (volatile sulphur comounds), the unpleasant smelling gases generated by oral bacteria and enzymes, renowned to be the main cause of bad breath.

The mouthwash combats and removes bacteria which can cause bad breath and plaque and remains fresh for up to 18 hours after a single use. In addition, as bacteria cling to the oil phase in the product, when the user rinses out, bacteria and debris are taken with it.

Finally it delivers residual protection as bacteria are physically removed and do not remain in the mouth as a food source on which the oral bacteria can feed, so prolonging the efficacy of the product. The oil phase provides an unobtrusive film on the teeth and gums, so the mouth is protected from further attack and remains fresher for longer than water-based products. The formula also includes fluoride to help care for the teeth and gums and strengthen teeth.

Menthol has been added at a relatively high level to ensure an icy-cool in-mouth sensation and this freshness boost increases with intensity after use.

Reader response number 52

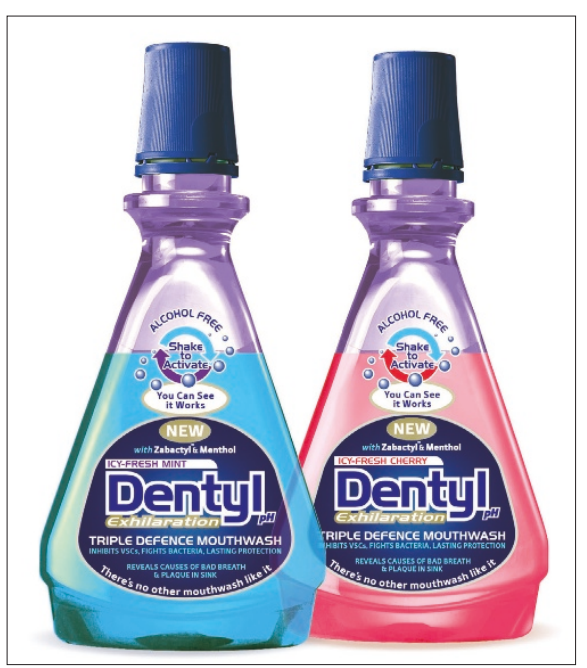



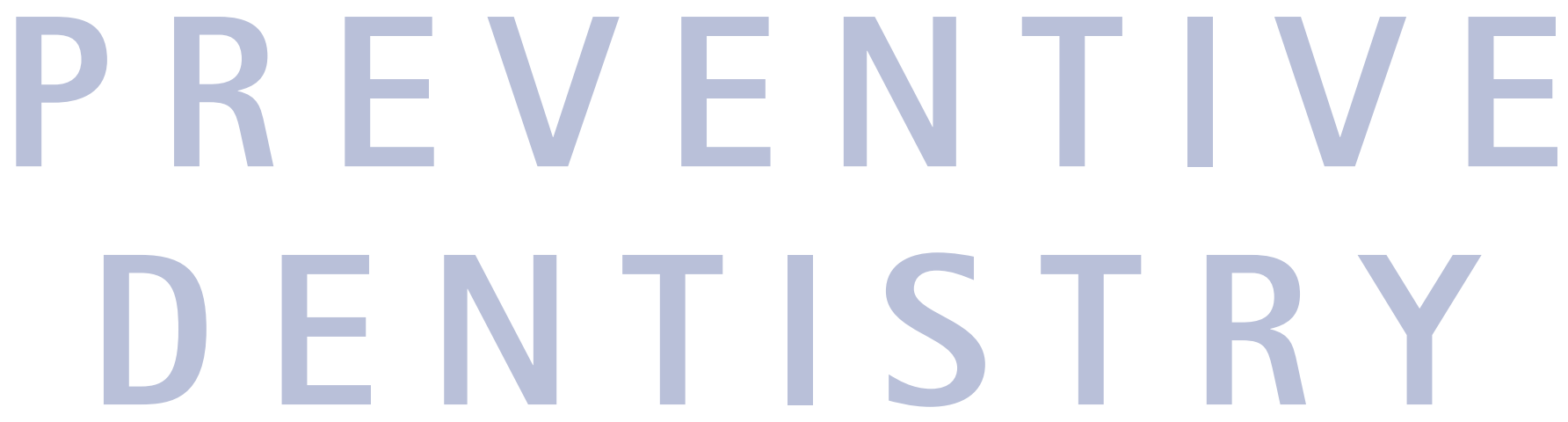

\section{High visibility probe}

The Periowise patented, multi-coloured periodontal probe is easy to read, gentle on tissue and safe to use around implant fixtures. Clear, well-defined markings in green and red give high visibility against tooth substance and soft tissue and ensure accurate pocket depth readings. A choice of 3-5-7-10mm or 3-6-9-12mm markings provide for individual preferences.

The flexible tip gives good tactile sense and reduces the risk of tissue trauma or damage to implant fixtures. Made from an autoclavable polymeric material which can also be ultrasonically cleaned, Periowise is supplied in packs of three or six and is available from all major dental dealers.

The product eliminates the most frustrating part of periodontal probing: poor readability. At a glance, you can quickly determine the depth of the pocket and make the appropriate diagnosis.

Reader response number 53

\section{Sharper scalers}

The PerioStar 3000 from KerrHawe sharpens hand scaling instruments, maintaining their original sharpness and geometry.

This means that the life expectancy of the instrument will be improved as very little material is removed throughout the speedy

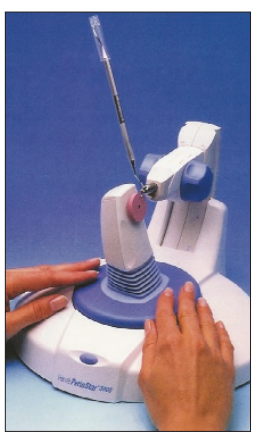
sharpening process, thus saving further expenditure on expensive new instruments.

According to the company, hand scalers show the first signs of bluntness after just 10-15 strokes and this can be the start of hand-fatigue related illnesses such as carpal tunnel syndrome. A demonstration video of the Periostar 3000 is available free of charge.

Reader response number 56

\section{Needle-free anaesthetic}

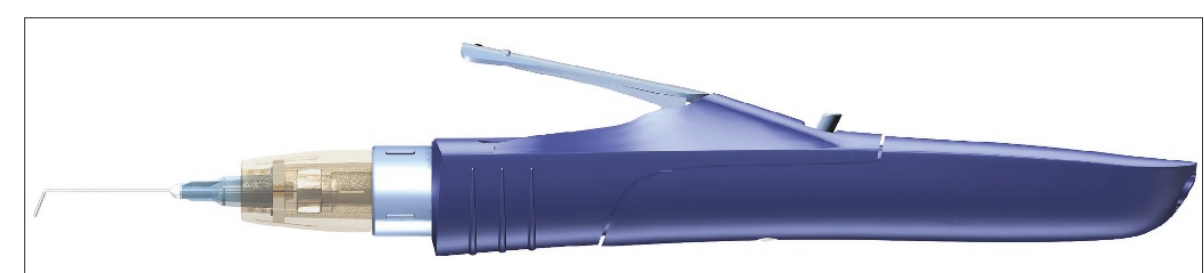

Dentsply's needle-free anaesthetic, Oraqix (25/25 mg per g periodontal gel (lidocaine, prilocaine) is a non-injectable dental anaesthetic gel. It contains $2.5 \%$ lidocaine and $2.5 \%$ prilocaine which, when applied to the gums via a special patient-friendly ergonomic dispenser, turns to gel at body temperature and numbs within 30 seconds. This patented thermosetting property keeps it in place for effective absorption. As a non-injectable product, it is site-specific and can be placed in a number of areas within the mouth in the same visit, offering dentists greater clinical flexibility.

Sensitive treatments such as scaling, probing or root planing can now be carried out without the need for an injection, which is great news for phobic patients.

Reader response number 54

\section{Effective oral care routines}

Oral-B has launched a series of three patient oral care instructions to help patients implement an effective home oral care routine. The company recognises that different electric toothbrushes require different techniques and that if you want to make the most of the technology you need to know how to use it. It believes that whatever the patient preference, oscillating-rotating or sonic, patients should still floss.

The three new instruction cards are A4 in size and are laminated to ensure durability and hygiene. They contain clear illustrations for demonstrating brushing and flossing techniques.

To reinforce in-surgery tuition, Oral$\mathrm{B}$ has produced the corresponding three leaflets for home guidance. One focuses on brushing with an electric oscillating/rotating toothbrush and the various other brush heads, one looks at how to brush correctly using a sonic brush, and the other covers flossing instruction. All are designed to increase consumer awareness of the importance of oral hygiene and to ensure patients take the best possible care of their teeth between appointments by implementing an effective home oral care routine.

To order copies of the instruction cards (maximum three per version per practice) or patient leaflets (no restrictions) please call 08707-264590.

Reader response number 55

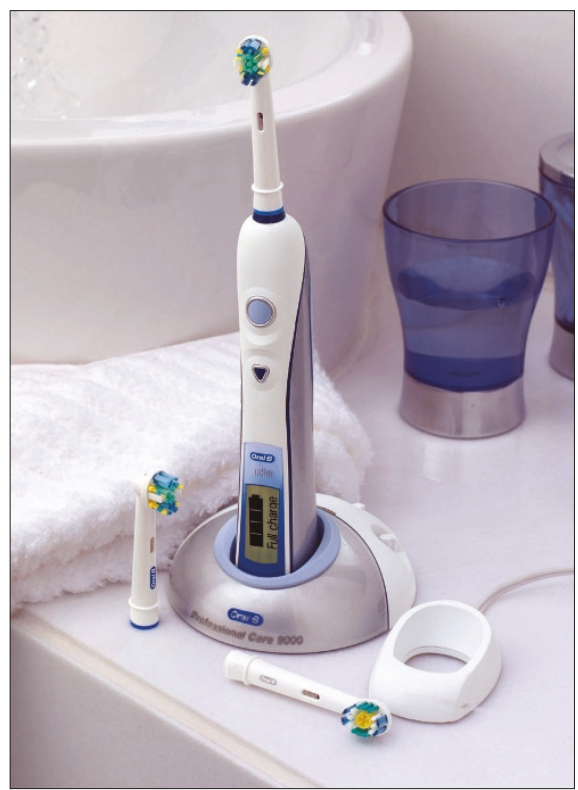




\section{Enamel and dentine protection}

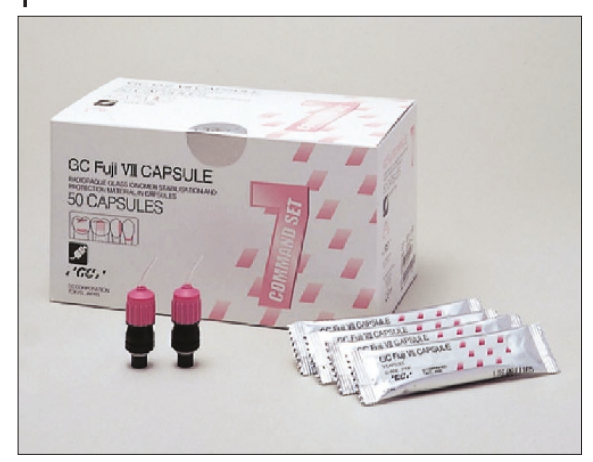

New GC Fuji VII is a radiopaque glass ionomer material in capsules for enamel and dentine protection. It can be used as a fissure protection material and for hypersensitivity prevention and control of exposed shoulder dentine. Fuji VII is a pale pink in colour for easy identification, has a working time of one minute and 40 seconds and a chemical cure setting time of two minutes and 30 seconds. Fuji VII can also be command set in 20 seconds using heat from light irradiation which speeds up the acidbase reaction. Other indications include endodontic sealing, root surface protection, caries stabilisation and as an intermediate restoration. GC Fuji VII is available as a box of 50 capsules.

Reader response number 58

\section{Non-slip grip}

Flexichange from Dentsply Ash are silicone handled instruments with a comfortable non-slip grip that may aid the reduction of Carpal Tunnel Syndrome, according to the company. A comprehensive range of over 70 periodontal and restorative therapy instruments are available and interchangeable tips allow for the customisation of instruments and the replacement of worn tips.

They also feature hard wearing white ceramic handles as well as six colour coded handles for easy identification. Their ergonomically designed octagonal shape enhances control, grip and long-term comfort and handles can be individually branded with the dental practice name or logo.

Reader response number 60

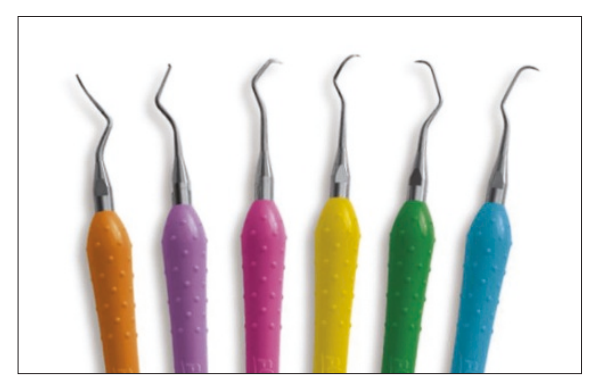

\section{Back friendly seat}

The BackCare Product Panel has given Bambach the thumbs up following vigorous testing. The National Back Pain Association says the seat could help many people to prevent back pain particularly those who have sitting and stretching tasks to carry out such as dentists.

The Bambach Saddle Seat was developed by Australian occupational therapist Mary Gale.

It is shaped like a horse's saddle and uses the biomechanics of the body to naturally position the spine while supporting the pelvis, promoting perfect spinal balance. When users are seated in this position, there is better mobility, reduced slouching and less back pain.

Reader response number 57

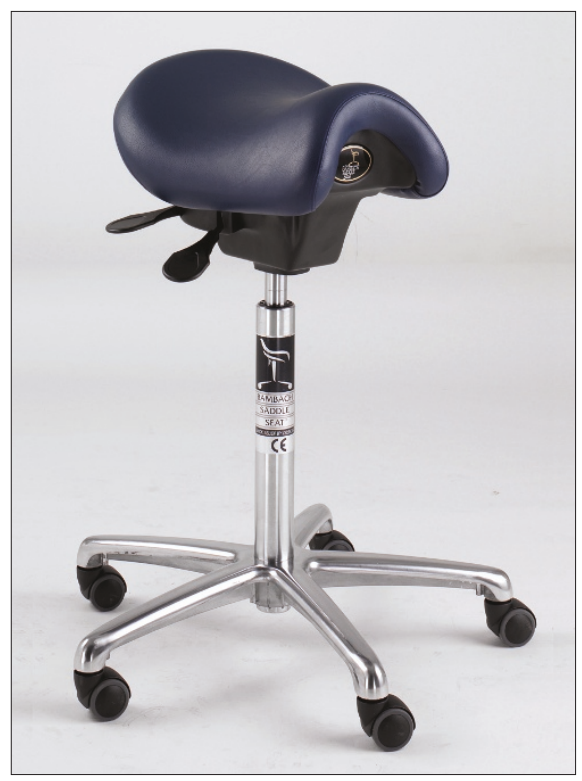

\section{Pain free suction adapter}

The SDI Directa Adaptapal suction adapter is the simple solution to pain free suction according to Trycare Dental Linkline. Bending easily, Adaptapal enables the operator to get good access from all angles facilitating better control. This can be better for the operator and makes the patient feel more comfortable. Easy to remove for cleaning, Adaptapal also serves as a barrier shield because you hold it rather than the aspirator hose.

Available in two sizes ( blue $6.3 / 11 \mathrm{~mm}$ and yellow $11 / 11 \mathrm{~mm}$ ), it is supplied in packs of four. It can be disinfected in wash-

er disinfectors or autoclaved up to $120^{\circ} \mathrm{C}$ and can be used up to 30 times.

Reader response number 59

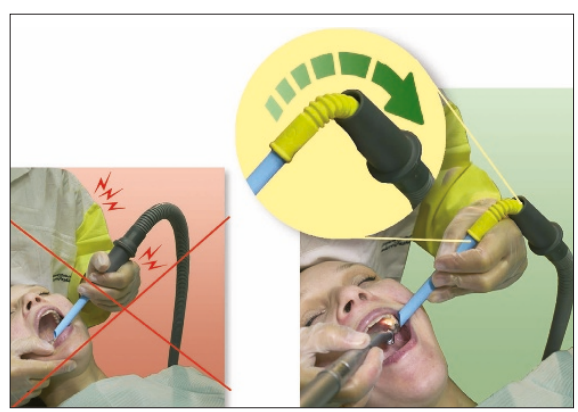

\section{Healing mouth ulcers faster}

Gengigel from Oraldent is a biological mouth and gum-care gel based on hyaluronan, which helps to accelerate the healing process of ulcers within the mouth.

Causes of mouth ulcers can vary from stress, irritants and bacterial, viral or fungal infections to nutritional deficiency, discoid herpes and erythematosas. Ulceration can present in the form of minor and major aphthous; minor ulcers tend to heal more quickly and occur at longer intervals than major ulcers, which occur in regular cycles.

The hyaluronan in Gengigel helps to reduce the incidence of ulcers, and also limits their effects, offering preventative action and relief in one easy to use gel.

Hyaluronan is effective by performing a number of structural and physiological functions within the tissues. It controls the interaction between extracellular and intercellular structures, whilst managing inflammatory cytokine interactions. It also acts to regulate osmotic pressure and tissue lubrication.

The combination of these actions encourages tissue to grow back faster, whilst simultaneously assisting in the prevention of re-infection, offering ulcer suffers long-term relief from the discomfort caused by the condition.

\section{Reader response number 61}

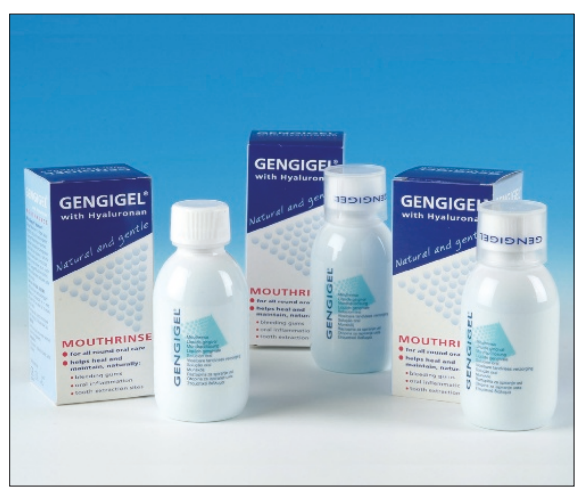

